lightest description, and though taken with reluctance caused no pain whatever. On Feb. 21st at $10 \mathrm{~J}$.M. the patient suddenly woke and vomited an immense quantity of liquid blood. The attendant, who had left him sleeping, found him on his return apparently at the point of death. Blood covered his face and the bedclothing, and there was a large pool of blood on the carpet. On my arrival he was almost pulseless, barely conscious, and deathly wbite. I administered a large enema of very hot water and sent for Dr. Michell Clarke. He advised transfusion which with the aid of Mr. Morton was at once begun but by means of which we hoped at the utmost to be able to keep the patient alive until morning when bis friends would arrive. Both median basilics were opened, and altogether something more than four pints of saline solution were introduced into the veins. The immediate effects were extremely disappointing, the volume of the pulse being but little improved, and death appearing to be imminent and inevitable. However, after 4 A.M. when Mr. Morton left, the patient dozed for an hour and awoke somewhat better. I remained with him all day, administering at intervals of about two hours small enemata of brandy and milk, and giving hypodermic injections of strychnine every six hours. $\mathrm{He}$ expectorated blood and mucus and passed some blood by the rectum. The patient had been reduced to extreme emaciation and anæmia before the occurrence of this great hæmorrhage and his bloodless aud deathlike appearance at this time it is impossible to exaggerate. At nightfall there was a further change for the worse. Respiration became laboured, the pulse was barely perceptible, consciousness failed, and there was rectal incontinence, the frecs having a characteristically offensive cadaverous odour. The patient was delirious at intervals and was stone deaf. For 24 hours he continued in this apparently moribund condition, the jaw dropped, there was Cheyne-Stokes respiration, and all hope of recovery seemed out of the question. But at about 7 P.M. of the 23rd there was a sudden change for the better. Hearing and, in some degree, consciousness returned. The terrible foetor of the rectal ejecta and the prolapsed condition of the bowel still precluded any attempt at rectal feeding, but the patient sipped a little champagne and later some aerated milk. He passed a good night and on the following day took small quantities of peptonised milk at intervals of from 20 to 30 minutes. From this time forward his recovery proceeded without a hitch. For 10 days he was fed exclusively on peptonised milk; then light farinaceo is foods, fish, fowl, and at length beef and mutton were gradually added, always without ill-effect. The patient gained weight at the rate of from five to six pounds per week and when he left on May 15th he weighed 8 st. without his clothes, which (for he is very small and lightly built) is practically his normal weight.

The most interesting point in connexion with this case is the question of the occurrence or non-occurrence of perforation. The reasons which lead me to the conclusion that perforation took place are (1) the severity of the symptoms preceding the incident; (2) the suddenness of the onset and its characteristic nature; (3) the very definite localisation of the pain and tenderness in the neighbourhood of the pylorus and its gradual subsidence during the week following its appearance; $(4)$ the occurrence of a localised peritonitis in the neighbourhood of the lesion; and (5) the extension of inflammatory symptoms to the base of the right lung. The fact of spontaneous recovery is doubtless to be explained as due to the stomach having been empty at the time when the accident took place. As regards the bæmatemesis which occurred on Feb. 21st, large as was the quantity of blood which the patient vomited it did not represent the full amount of the hæmorrhage, for the stomach appeared at the time of the consultation with Dr. Michell Clarke to be full of blood and a good deal of blood was subsequentiy passed by the rectum. It may be said that the hæmorrhage would not have happened if rectal feeding had been exclusively employed, but the difficulty was that rectal feedicg was so ill borne that there was obvious danger of the patient's sinking from exhaustion. There can be no doubt, I think, that the transfusion saved this patient's life, as the rally on the following day was very marked, though it was followed by a second collapse in which the patient showed all the signs of impending death. I think no one who had seen him as he appeared on Feb. 23rd would have hesitated for a moment to say that death within a very fe hours was absolutely inevitable.

Clifton, $\mathrm{Br}$.t. $\%_{0}$

\section{OBSCURE CASES OF PTOMAINE POISONING.}

BY A. R. ALDRIDGE, M.B., C.M. EDIN., D.P.H., MAJOR R.A.M.C.

I AM induced to ask you to publish short notes of these four cases in the bope that some readers may be able to offer suggestions as to their nature and cause. The cases occurred in Englishmen lıving under practically identical conditions during the hot months in a Punjab station at intervals of a few weeks and their similarity points to a similar nature and common cause.

CASE 1.-The patient was a man, aged 30 years, a heavy drinker, who had been seven years in India and had suffered from malarial fever but not latterly. On admission to hospital on March 19th he complained vaguely of feeling very ill but his symptoms were difficult to localise, pain in the loins and soreness of the throat being the chief. The liver and spleen showed some enlargement, the fauces were rather congested, and the temperature was $98^{\circ} \mathrm{F}$. The urine contained neither sugar nor albumin and nothing abnormal could be found in the other organs. On the night of the 20th pain commenced in the epigastrium and there was vomiting of bile-stained matter; this continued during the next day, the romit containing a little altered blood, but at no time was the vomiting very urgent. On the evening of the 21st he became collapsed with severe pain and tympanitic distension of the epigastrium and dyspncea, and he died during the nioht. His temperature during the whole illness remained subnormal from $96.8^{\circ}$ to $98^{\circ}$ and his bowels were constipated. Post mortem a considerable amount of fat was found around the heart and the left side appeared to be hypertrophied. The liver was cirrhotic and adherent to the under surface of the diaphragm. The transverse colon was encrmously distended with gas and the stomach was moderately so and contained food mixed with "coffee-ground" matter and showed several congested patches and submucous hæmorrhages along the greater curvature. There was no obstruction at any part of the intestine. A dog fed on the stomach contents mixed with milk suffered no ill effects.

CASE 2.-The patient was a man, aged 27 years. His previous health had been very good. He had never had malarial fever. The illness commenced on May 1st with vomiting of bile-stained, and after a few days slightly bloodstained, matter. Under treatment this had stopped by May 6th, but he remained very prostrate with a sense of oppression in the chest and dyspnoea. His temperature ranged from $98^{\circ}$ to $99^{\circ} \mathrm{F}$. Nothing could be learned by physical examination and the urine was normal. The dyspnoea and collapse increased and he died on the seventh day. No post-mortem examination was made.

CASE 3 -The patient was a man, aged 21 years. His previous health had been good. The early symptoms were practically identical with those of the former case and examination gave similarly negative results. The vomiting was never very urgent, but the amount of collapse was out of all proportion to it. His temperature ranged between $97^{\circ}$ and $986^{\circ} \mathrm{F}$., and his bowels were constipated. Dyspncea came on and he died on June 19th, the seventh day of his illness. Post mortem adhesions of the right pleura were found and there was a large "white" clot in the right side of the heart. On the mucous membrane of the stomach were a number of bæmorrhagic spots, especially on its posterior surface. The spleen was small and firm, weighing $5 \frac{1}{2}$ ounces. Blood from the spleen was examined for malarial organisms and pigment, but none were found.

CASE 4.-This case was almost a repetition of the former ones. The illness commenced on July 6th. The temperature ranged from $97.6^{\circ}$ to $99^{\circ} \mathrm{F}$. The bowels were constipated and there were considerable epigastric pain and cramps of the muscles of the extremities. The vomiting, as in the former cases, lessened, but he did not rally; dyspnœea with lividity of the face commenced and he died on the fifth day. Post mortem congested patches were found on the mucous membrane of the lesser curvature of the stomach and large areas in the small intestine from the duodenum to the ileo-cæcal valve. A large "white" clot was found in the right auricle and ventricle.

Several points common to these cases may be noted. 
1. The temperature was mostly subnormal, and never exceeded $99^{\circ}$. 2. The excessive collapse without signs of disease to account for it; all appeared very ill and were despondent about themselves from the first. 3. The dyspncea coming on as the vomiting lessened, and the somewhat sudden fatal termination. That the cases were "algid" cases of malaria seems negatived by the fact that the place in which the patients were living was not a very malarious one and the type of fever occurring there was a very mild one; also by the absence of any fever and in all except the first of any enlargement of the spleen; and also in the only one in which an examination of the blood could be made by the absence from the blood of malarial organisms and pigment. The absence of clinical and post-mortem signs of kidney disease renders uræmia an insufficient explanation. Many of the symptoms point to ptomaine poisoning, though the somewhat long course and the absence of diarrhoea seem against this theory. The only article of food suspected was cow's heel which two of the patients had eaten just before the illness as had one other possibly, and which is a substance from its gelatinous composition offering a particularly suitable nidus for bacterial growth. It was unfortunate that clinical and bacteriological examinations of the stomach contents could not be-made.

Cherat, Punjab, India.

\section{A CASE OF PENTASTOMA CONSTRICTUM.}

By ALBERT J. CHALMERS, M.D. VICT., F.R.C.S. ENG., ASSISTANT COLONIAL SURGKON, THE GOLD COAST COLONY.

BY the kind permission of the Right Honourable the Secretary of State for the Colonies I am permitted to publish an account of this case of pentastoma constrictum.

Early in 1898 a negro, by race a Mendi from Sierra Leone, applied for medical relief at the Colonial Hospital at Accra on the Gold Coast of West Africa. He was admitted into the hospital and in the course of a few days he died. At the necropsy large numbers of the parasite pentastoma constrictum were found in the langs, liver, alimentary canal and peritoneal cavity. As there are not many descriptions of this parasite and of the disease which it causes I consider that a brief account may be useful to anyone interested in tropical diseases.

Pentastoma constrictum was first discovered in 1847 by Pruner $^{1}$ in Egypt in the livers of two negroes upon whom he made post-mortem examinations. He apparently did not recognise the zoological position of the parasite, but sent specimens to Bilharz and Von Siebold, ${ }^{2}$ who published an account of it, and gave it the name of "pentastoma constrictum" in their Text-book of Zoology. The next recorded investigation is that given by Aitken ${ }^{3}$ of a case under the care of Dr. Kearney. This observer records the clinical history of the illness and death together with the post-mortem appearances of a negro private of the West Indian Regiment who died in January, 1865, at Jamaica, but who had come from St. Helena only eight months previously. After this there is apparently a long interval without any further records till Girard published an account of the illness and death from purulent meningitis of a Senegalese tirailleur sent to him by Dr. Marchoux and Dr. Clouard. These gentlemen had found in the liver of the tirailleur the characteristic cysts containing the parasite. The patient died at St. Louis on the West Coast of Africa, having just arrived from Kayes a town in the French Soudan or Hinterland behind the French Guinea. Such is the history of the parasite as far as I can find it. Numerous references are made in many text-books but the above are, I fancy, the only original observations.

With regard to my own case, that of the Mendi abovementioned, the clinical history was as follows. On admission into the hospital the patient was much emaciated and very weak. He had a markedly enlarged and protuberant abdomen. The temperature was slightly above normal and

Krankheiten des Orients, 1847, p. 245.

2 Zeitschrift tir Wissenschaftliche Zoologie, Band iv., s. 65. Science and Practice of Medicine, 1868, vol. i.. p. 650 .

4 Comptes Rendus de la Société de Biologie, 1896, vol. x., series iii., pp. $469-471$. he suffered from a hacking cough with expectoration of a little mucus. He apparently suffered from pain in the abdomen and the lower part of the chest, but it was extremely difficult to be certain of his sensations as no one understood his language. The physical signs which were present in the respiratory organs were those of congestion of the lungs with impaired resonance on both sides and mucoid expectoration in which no parasites were to be seen. There was pain on pressure over the ahdomen. The bowels acted regularly but unfortunately the fæces were not examined. The liver was enlarged but not tender. The spleen was very much increased in size. The heart was normal but the patient was anæmic. When the blood was examined no parasites were to be seen or anything worthy of note. The urinary system was normal, as was the cutaneous system. The patient remained in much the same condition for a few days, but suddenly the temperature rose to $104^{\circ} \mathrm{F}$. and he became rapidly worse and died. He was mainly treated for congestion of the lungs and it was this disease which was the cause of his death.

The post-mortem examination was made about 17 hours after death. The body was much emaciated and the abdomen was protuberant. On opening the abdomen large numbers of parasites (pentastoma constrictum) were observed moving freely in the abdominal cavity over the surfaces of the various organs, to which some were also observed to be attached. The liver contained in its substance and projecting on to its surface a large number of cysts each containing a clear fluid in which lay a single parasite coiled up. Some of these were liberated and found to be alive, and were exactly the same as the pentastomata found free in the peritoneal cavily. No parasites were found in the gall-bladder or in the bile duct. The substance of the liver was congested and the organ was enlarged. The stomach and intestines were not congested, though they were matted together by old peritonitic adhesions. Attached to the surface of the intestines at a few spots parasites were seen firmly fixed by their hooks. On opening the stomach no parasites were seen, but in the small intestine, except the duodenum, there were large numbers of pentastomata. None were seen in the large intestine. At places in the small intestine there were signs as though the parasites were in the act of passing from the lumen of the bowel through the wall of the intestine into the peritoneal cavity. The spleen was markedly enlarged and congested but entirely free from parasites. The kidneys and pancreas were normal. Several parasites were found attached to the peritoneal surface of the bladder, but none were found in the interior or in the wall. The peritoneum everywhere showed signs of old peritonitis, but this was most marked in the region of the liver and the spleen. The diaphragm, except for peritoneal adhesions, was normal, and no parasites. were noticed attached to it. In the chest the heart was normal, but the pericardium was much thickened. The pleura was much thickened on both sides and the lungs were bound down by many old fibrous adhesions. The lungs were markedly congested and cedematous and the bronchi were inflamed. Both projecting on the surface and imbedded in the substance of both lungs there were numerous cysts like those found in the liver and in each of these a parasite was found. No parasites were found in the muscles or among the adipose tissue of the body. The brain and the spinal cord were not examined.

I do not intend to describe the anatomy of pentastoma constrictum in this paper but hope to do so shortly. Nothing is known at present as to the life-history of this parasite or as to the means by which it enters the human body. It appears to me that it enters by some means into the alimentary canal and that from this it proceeds to the liver, the cysts in which appear to be dilated biliary ducts, and into the peritoneum. It also seems as though the lungs were affected through the trachea, as the cysts therein appear like dilated bronchioles. The presence of the parasite in the human body sets up inflammation of the lungs and peritoneum, but it does not appear to irritate the alimentary canal or the liver. The disease appears to last some time before causing the death of the patient, for as far as I could make out the above-mentioned Mendi had been ill a long time. The only possible means of diagnosis would be the presence of the parasite in the fæces in cases of wasting and emaciation in negroes.

There is no described treatment of this disease. It appears to be confined to negroes and the described cases came from 